\title{
Photoswitchable Spiropyran Dyads for Biological Imaging
}

\author{
Yaoyao Xiong, ${ }^{\dagger, \S}$ Pablo Rivera-Fuentes, ${ }^{\dagger, \S}$ Erdinc Sezgin, ${ }^{\ddagger}$ Andreas Vargas Jentzsch, ${ }^{\dagger}$ Christian Eggeling, ${ }^{\ddagger}$
} and Harry L. Anderson* ${ }^{\dagger} \dagger$

${ }^{\dagger}$ Department of Chemistry, Chemistry Research Laboratory, University of Oxford, Oxford OX1 3TA, U.K.

${ }^{\ddagger}$ MRC Human Immunology Unit and Wolfson Imaging Centre Oxford, Weatherall Institute of Molecular Medicine, University of Oxford, Oxford OX3 9DS, U.K.

\section{Supporting Information}

ABSTRACT: The synthesis of a small-molecule dyad consisting of a far-red-emitting silicon rhodamine dye that is covalently linked to a photochromic spironaphthothiopyran unit, which serves as a photoswitchable quencher, is reported. This system can be switched reversibly between the fluorescent and nonfluorescent states using visible light at wavelengths of 405 and $630 \mathrm{~nm}$, respectively, and it works effectively in aqueous solution. Live-cell imaging demonstrates that this dyad has several desirable features, including excellent membrane permeability, fast and reversible modulation of fluorescence by visible light, and good contrast between the bright and dark states.
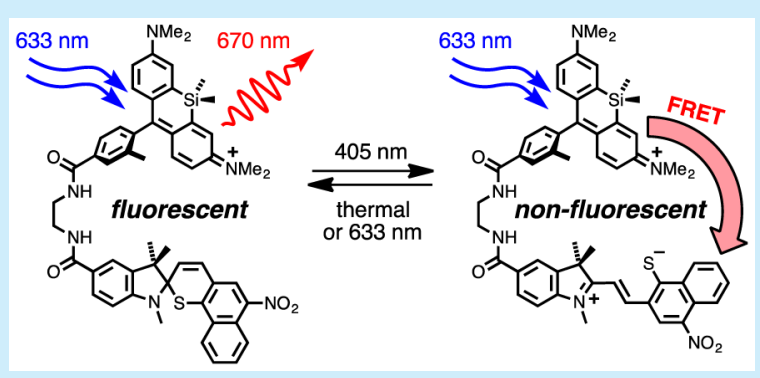

ptical fluorescence microscopy of living cells relies on the development of advanced labels. This is specifically true for super-resolution microscopy, or nanoscopy, which has made it possible to observe the organization of cellular constituents and the dynamics of biomolecules in cells with unprecedented spatial resolution. ${ }^{1-3}$ Techniques such as STimulated Emission Depletion (STED) $)^{1 a, 2}$ and its generalized modality, REversible Saturable OpticaL Fluorescence Transitions (RESOLFT), ${ }^{3}$ require fluorophores that can be photoswitched reversibly and rapidly between two states with different fluorescence characteristics, such as an emissive state and a dark state. In STED, a second laser is used to force electronically excited molecules in specific spatial regions to decay to the ground state via stimulated emission instead of fluorescence, which is equivalent to inducing a dark state. However, stimulated emission requires intense illumination, which may cause permanent photobleaching of the fluorophore and damage to the specimen. ${ }^{4}$ Several approaches have been proposed to minimize this effect. ${ }^{5}$ In principle, the light intensities required can be substantially reduced if photochemical reactions are used to switch the fluorescence "on" and "off" instead of using stimulated emission. ${ }^{6}$ This concept has been successfully applied in RESOLFT using reversibly switchable fluorescent proteins. ${ }^{3,7}$ The use of synthetic dyes would have many potential advantages over fluorescent proteins, such as high brightness and photostability ${ }^{8}$ and the possibility of labeling endogenous proteins.'

Several designs of small-molecule dyes for RESOLFT microscopy have been proposed, ${ }^{10}$ but the realization of a working example for live-cell imaging has remained challenging. ${ }^{11}$ One promising approach to a photoswitchable dye is to covalently link a standard fluorophore to a photoswitchable quencher. ${ }^{11,12}$ Many photochromic dyes that switch in response to UV light have been developed. However, for biological microscopy applications it is preferable to control the switch with visible light $(\lambda>400 \mathrm{~nm})$ because shorter wavelengths are damaging to cells and are not compatible with the optics in standard fluorescence microscopes.

Spirobenzopyrans have been investigated extensively as molecular photoswitches for diverse applications. ${ }^{13,14}$ They undergo reversible photoisomerization between a closed spiropyran (SP) form that is nearly colorless and an open merocyanine (MC) form that is intensely colored (Scheme 1). Extending the $\pi$ conjugation from benzopyran to naphthopyran induces a red shift in the absorption spectrum of the closed SP form and shifts the wavelength of light required for ring opening into the visible region, ${ }^{13}$ providing an ideal platform for multicolor fluorescence quenching. The MC $\rightarrow$ SP reaction occurs spontaneously in the dark and can be photochemically driven. ${ }^{15}$

Here we report a photoswitchable, far-red-emitting smallmolecule dyad comprising the bright biocompatible fluorophore silicon rhodamine $(\mathrm{SiR})^{8,16}$ and a spironaphthothiopyran as a photoswitchable quencher. Despite the large amount of research on spirobenzopyrans, ${ }^{13,14}$ spironaphthopyrans have received little attention, ${ }^{13}$ and spironaphthothiopyrans have not been previously reported.

The compounds used in this study were prepared as shown in Scheme 1. The synthesis starts with Duff formylation of naphthol $\mathbf{1}$ to give aldehyde 2 . The sulfur analogue 3 was synthesized from the reaction of $\mathbf{2}$ with dimethylthiocarbamoyl chloride via a Newman-Kwart rearrangement and deprotection. Fischer base 4 was used to prepare photochromes 5 and 6 by Knoevenagel

Received: June 13, 2016

Published: July 26, 2016 
Scheme 1. Photoisomerization of Spironaphtho(thio)pyrans and Synthesis of Dyad 8

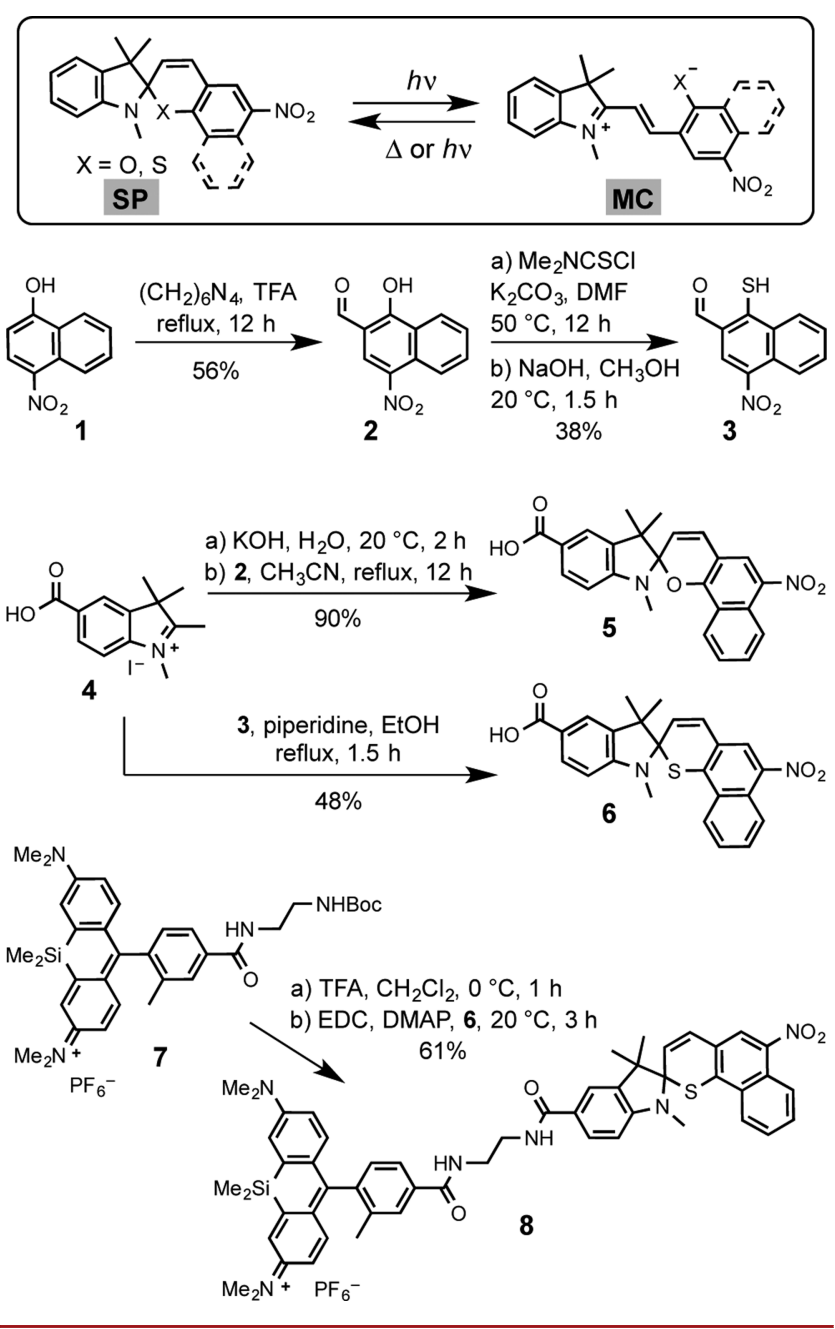

condensation with aldehydes 2 and 3. Compound 6 was subsequently conjugated to $\mathrm{SiR}$ derivative 7 to afford dyad 8 .

Photolysis of spironaphthopyran 5 and spironaphthothiopyran $\mathbf{6}$ in organic solvents results in a rapid color change as the paleyellow SP isomers are converted to the blue-green MC forms. With compound 5, the SP/MC ratio at equilibrium in the dark is sensitive to the solvent polarity, with the MC form becoming more stable in polar solvents (Figures S1 and S3). In aqueous solution, $\mathbf{5}$ exists mainly as the MC isomer, and no evidence of photoswitching was detected (Figure S4). In contrast, spironaphthothiopyran 6 exhibits excellent positive photochromism in polar and apolar media. ${ }^{1} \mathrm{H}$ NMR spectroscopy in polar solvents shows that 6 exists exclusively in the SP form (Figure S2), as confirmed by the UV-vis absorption spectra; the $\mathrm{MC}$ form is not detected at equilibrium in pure water (Figure $\mathrm{S} 5)$, and the SP form is insensitive to $\mathrm{pH}$ in aqueous solution ( $\mathrm{pH}$ 5.5-8.5; Figure S38).

Photoswitching experiments were carried out using 405 and $630 \mathrm{~nm}$ light-emitting diodes (LEDs) as light sources, with intensities of 1.1 and $2.1 \mathrm{~W} / \mathrm{cm}^{2}$, respectively (see the Supporting Information (SI)). The intensity and duration of the irradiation were adjusted to optimize the switching performance and minimize photobleaching (Figure S7). The absorption spectrum of $\mathbf{6}$ in methanol in the dark is compared with that recorded under irradiation at $405 \mathrm{~nm}$ in Figure 1. The

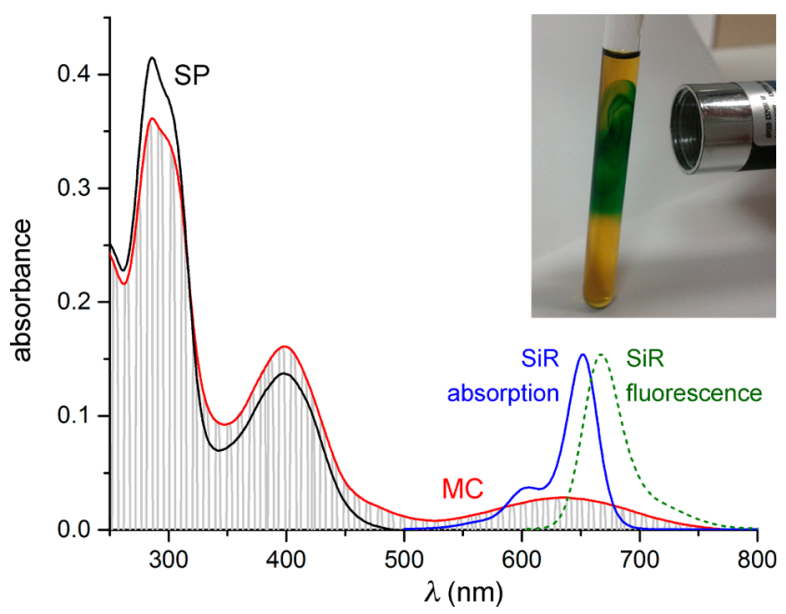

Figure 1. UV-vis absorption spectra of 6 in $\mathrm{CH}_{3} \mathrm{OH}(14 \mu \mathrm{M})$ before (black line, SP) and after (red line, MC/PSS) irradiation at $405 \mathrm{~nm}$. Before the second spectrum was recorded, the sample was irradiated for $5.5 \mathrm{~s}\left(1.1 \mathrm{~W} / \mathrm{cm}^{2}\right)$; it was then irradiated with $100 \mathrm{~ms}$ pulses every 300 $\mathrm{ms}$ while the spectrum was recorded in order to maintain the presence of the MC form. The inset shows a solution of 6 in DMSO under irradiation with a blue laser pointer $(405 \mathrm{~nm}, 1 \mathrm{~mW})$; irradiation causes a color change from yellow to green. The absorption (blue) and fluorescence (green) spectra of silicon rhodamine 7 are included for comparison.

photostationary state (PSS) displays a new peak at $\lambda_{\max }=630 \mathrm{~nm}$ due to the MC form. This band overlaps with the emission wavelength of the SiR fluorophore 7 (Figure 1), implying that there should be efficient fluorescence resonance energy transfer (FRET) in the MC form of dyad 8. The Förster radius calculated from the spectral overlap is $R_{0}=36 \AA$, and the distance between the $\mathrm{SiR}$ and MC units is 9-19 $\AA$, corresponding to an energy transfer efficiency of $>97 \%$ (section S1d in the SI). The quantum yield of the photochemical ring-opening reaction for compound 6 was estimated to be around $1 \%$ (section S1e), which is comparable to those for similar spirobenzopyrans. ${ }^{17}$

Following photochemical ring opening, the thermal recovery of the MC forms of compounds $\mathbf{5}$ and $\mathbf{6}$ occurs rapidly in polar solvents. The half-life of thermal ring closure $\left(t_{1 / 2}\right)$ for compound 6 at $20{ }^{\circ} \mathrm{C}$ ranges from $83 \mathrm{~s}$ in ethylene glycol to $14 \mathrm{~s}$ in $\mathrm{CH}_{3} \mathrm{OH}$, increasing nonlinearly as a function of solvent viscosity $^{18}$ (Figures S12 and S13). As with many spirobenzopyrans, ring closure of the MC form of 6 is accelerated by irradiation with red light (Figure 2). ${ }^{15}$ Excitation at $630 \mathrm{~nm}$ increases the rate of ring-closure by more than a factor of $3\left(k=0.14 \mathrm{~s}^{-1}\right)$ relative to thermal recovery in the dark $\left(k=0.042 \mathrm{~s}^{-1}\right)$. The ability to switch the system photochemically in both directions using different wavelengths is ideal for RESOLFT microscopy.

Spectroscopic analysis of dyad 8, comprising photochrome 6 connected to $\mathrm{SiR}$ derivative 7 , demonstrates that the spironaphthothiopyran remains in the SP form in polar solvents and pure water, as expected from the properties of switch 6 . The fluorescence quantum yield of dyad $8(\phi=0.17)$ in aqueous solution is only slightly lower than that of $\mathrm{SiR}$ derivative 7 ( $\phi=$ 0.24 ), which indicates that the SP form of the photochrome does not significantly quench the emission of the fluorophore.

Good fatigue resistance, i.e., a large number of switching cycles before photodegradation, is an important requirement for a photoswitchable dye for RESOLFT microscopy. We tested the fatigue resistance of $\mathbf{6}$ in methanol. Under aerobic conditions, it shows significant decomposition after 10 cycles (Figure 3), 


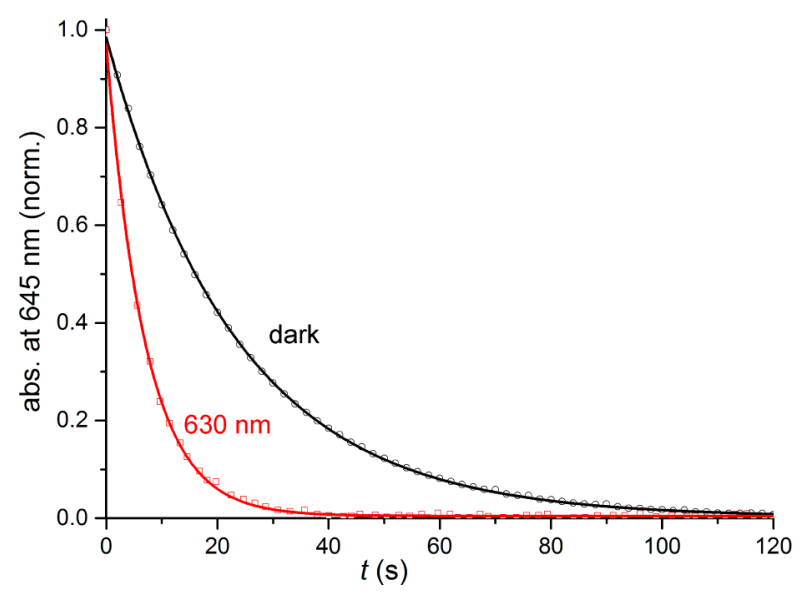

Figure 2. Kinetic traces for the ring-closure reaction $\mathrm{MC} \rightarrow \mathrm{SP}$ after irradiation of compound 6 in $\mathrm{CH}_{3} \mathrm{OH}(14 \mu \mathrm{M})$ either thermally (black, open circles) or photochemically with irradiation at $630 \mathrm{~nm}(2.1 \mathrm{~W} /$ $\mathrm{cm}^{2}, 200 \mathrm{~ms}$ irradiation $+500 \mathrm{~ms}$ intervals) (red, open squares). Each trace has been fitted to a first-order decay $\left(k=0.042\right.$ and $0.14 \mathrm{~s}^{-1}$, respectively).

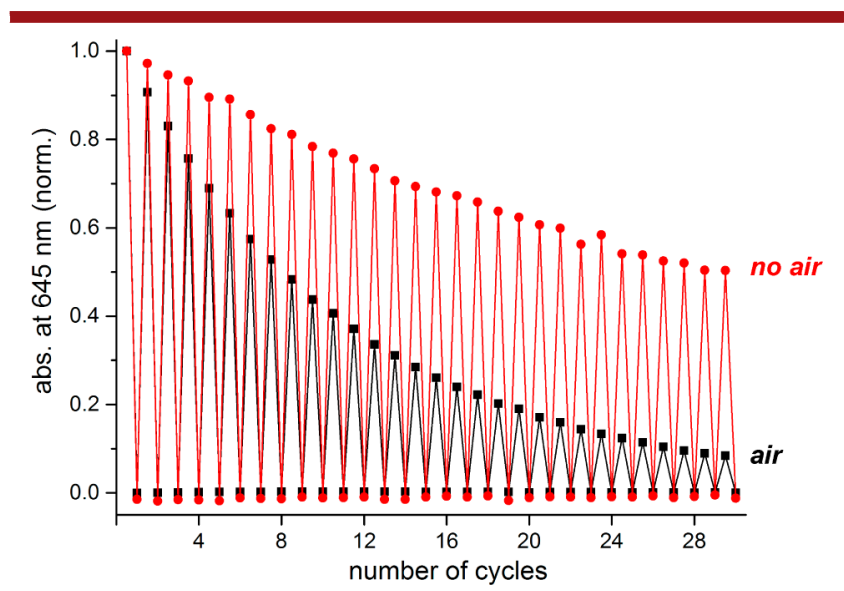

Figure 3. Photochemical fatigue resistance of compound 6 in $\mathrm{CH}_{3} \mathrm{OH}$ $(14 \mu \mathrm{M})$ in the presence (black squares) and absence (red circles) of air. Samples were irradiated for $5.5 \mathrm{~s}$ at the beginning of each cycle using a $405 \mathrm{~nm} \mathrm{LED}\left(1.1 \mathrm{~W} / \mathrm{cm}^{2}\right)$, and then thermal ring closure was allowed to reach completion before the next cycle.

whereas there is less fatigue under anaerobic conditions, implying that switch 6 suffers oxygen-dependent photochemical decomposition, possibly due to oxidation of the thiol in the MC form.

The ability of dyad $\mathbf{8}$ to operate in biological environments was tested on a confocal microscope using human dermal lymphatic endothelial cells (HDLEC) and Chinese hamster ovarian ( $\mathrm{CHO}$ ) cells. Compound $\mathbf{8}$ crosses the plasma membrane readily $\left(15 \mathrm{~min}\right.$ at $\left.37{ }^{\circ} \mathrm{C}\right)$ in both types of cells. It appears to accumulate in the mitochondria of HDLEC and in endosomal compartments in $\mathrm{CHO}$ cells. Here we discuss the results obtained in HDLEC; results in CHO cells are presented in the SI. Dyad 8 shows good contrast using a $633 \mathrm{~nm}$ laser to excite the fluorophore, and photoisomerization of the quencher could be accomplished using a $405 \mathrm{~nm}$ laser, confirming the photochromic behavior. The photoswitching efficiency depends on the intensities of the excitation $\left(I_{633}\right)$ and switching $\left(I_{405}\right)$ irradiation as well as on the duration of the irradiation. The optimal photoswitching conditions were found to be $I_{405}=100-150 \mu \mathrm{W}$, $I_{633}=6.25 \mu \mathrm{W}$, and a pixel dwell time of $5 \mu \mathrm{s}$, as detailed in the SI (Figures S19-S23). With these parameters, the three images shown in Figure 4 were obtained. The first image (Figure 4A) shows the fluorescence of dyad 8 upon excitation at $633 \mathrm{~nm}$.
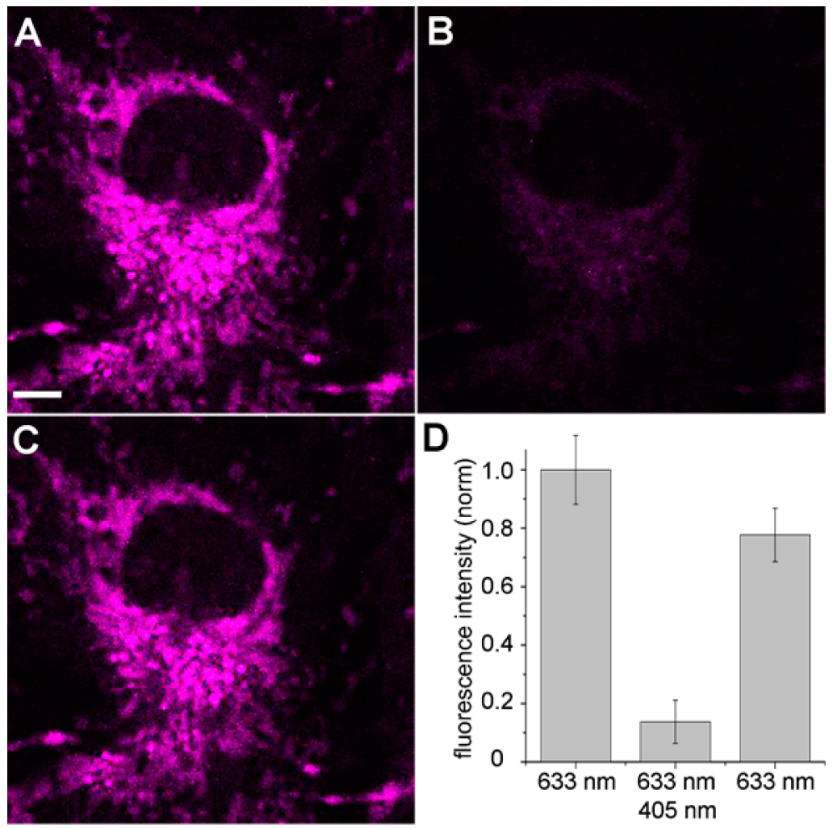

Figure 4. Confocal images of dyad 8 in live HDLEC. (A) Excitation at $633 \mathrm{~nm}(6.25 \mu \mathrm{W})$. Scale bar: $5 \mu \mathrm{m}$. (B) Irradiation at $405 \mathrm{~nm}(150 \mu \mathrm{W})$ immediately followed by excitation at $633 \mathrm{~nm}(6.25 \mu \mathrm{W})$. (C) Irradiation at $633 \mathrm{~nm}(6.25 \mu \mathrm{W}) \sim 2 \mathrm{~s}$ after (B). (D) Quantification of the off/on ratio (ratio of the fluorescence intensity in (B) to that in (A)).

Scanning the field of view with a $405 \mathrm{~nm}$ laser followed by immediate readout exciting with a $633 \mathrm{~nm}$ laser produced the second image (Figure 4B). Finally, the cells were scanned again, after 1-2 s, with the $633 \mathrm{~nm}$ laser (Figure 4C). This experiment revealed that irradiation at $405 \mathrm{~nm}$ switches the fluorescence intensity to about $13 \%$ of its original value in primary cells and that this switch-off is reversible (Figure 4D). We observed almost full recovery of the fluorescence intensity (Figure 4C) only $2 \mathrm{~s}$ after photoswitching, which is consistent with the rapid photochemical ring closure demonstrated in cuvettes.

The off/on ratio of about 0.13 implies that after $405 \mathrm{~nm}$ irradiation 8 must be at least $87 \%$ in the MC form and that the fluorescence from the Si-R component must be at least $87 \%$ quenched in this isomer. ${ }^{19}$ The $\mathrm{MC}$ form has significant absorption at $405 \mathrm{~nm}$ (Figure 1), making it impossible to achieve complete SP $\rightarrow$ MC conversion by excitation at this wavelength. A darker off state and a lower off/on ratio would be ideal, but a ratio of 0.13 is already high enough for RESOLFT microscopy. ${ }^{3 a, 20}$

The fatigue resistance was also investigated during live-cell imaging of dyad 8. Several cycles of alternating irradiation at 633 $\mathrm{nm}$ and $405 \mathrm{~nm}+633 \mathrm{~nm}$ revealed that the fluorescence off/on ratio decreases rapidly after only a few cycles (Figures S24 and S25). The ratio decreases mainly because the fluorescence intensity of the "off" state increases. This result is consistent with the cuvette experiment and confirms that the photoswitch, rather than the SiR fluorophore, is responsible for the poor fatigue resistance of dyad $\mathbf{8}$.

In conclusion, we have developed a reversibly photoswitchable dyad based on a silicon rhodamine fluorophore and a spironaphthothiopyran switch. This dyad possesses a number 
of desirable traits, including fast and reversible modulation of its fluorescence using visible light, high brightness in the far-red region, and a high off/on ratio in live cells using low laser powers. These results show that spironaphthothiopyrans have significant advantages compared with their oxygen counterparts. Unfortunately, dyad $\mathbf{8}$ does not display good enough fatigue resistance for RESOLFT microscopy; this limitation will be addressed in future work.

\section{ASSOCIATED CONTENT}

\section{S Supporting Information}

The Supporting Information is available free of charge on the ACS Publications website at DOI: 10.1021/acs.orglett.6b01717.

Detailed description of experimental protocols, absorption and emission spectra, investigation of solvatochromism, kinetic traces, optimization of irradiation intensities, fatigue resistance experiments, and ${ }^{1} \mathrm{H}$ and ${ }^{13} \mathrm{C}$ NMR spectra (PDF)

\section{AUTHOR INFORMATION}

\section{Corresponding Author}

*harry.anderson@chem.ox.ac.uk

Author Contributions

${ }^{\S}$ Y.X. and P.R.-F. contributed equally.

Notes

The authors declare no competing financial interest.

\section{ACKNOWLEDGMENTS}

We thank Tess A. Stanly for the HDLEC. This work was supported by the Wolfson Foundation, the Medical Research Council (MRC) (Grant MC UU 12010/Unit Programmes G0902418 and MC_UU_12025), MRC/BBSRC/ESPRC (Grant MR/K01577X/1), and the Wellcome Trust (Grant ref 104924/14/Z/14). E.S. was supported by EMBO Long Term and Marie Curie Intra-European Fellowships (MEMBRANE DYNAMICS). Y.X. was supported by the EPSRC Centre for Doctoral Training in Synthesis for Biology and Medicine (EP/ L015838/1) and by a University of Oxford Clarendon Fund Scholarship.

\section{REFERENCES}

(1) (a) Hell, S. W.; Wichmann, J. Opt. Lett. 1994, 19, 780. (b) Betzig, E.; Patterson, G. H.; Sougrat, R.; Lindwasser, O. W.; Olenych, S.; Bonifacino, J. S.; Davidson, M. W.; Lippincott-Schwartz, J.; Hess, H. F. Science 2006, 313, 1642. (c) Rust, M. J.; Bates, M.; Zhuang, X. Nat. Methods 2006, 3, 793. (d) Hess, S. T.; Girirajan, T. P. K.; Mason, M. D. Biophys. J. 2006, 91, 4258.

(2) Klar, T. A.; Jakobs, S.; Dyba, M.; Egner, A.; Hell, S. W. Proc. Natl. Acad. Sci. U. S. A. 2000, 97, 8206.

(3) (a) Hofmann, M.; Eggeling, C.; Jakobs, S.; Hell, S. W. Proc. Natl. Acad. Sci. U. S. A. 2005, 102, 17565. (b) Grotjohann, T.; Testa, I.; Leutenegger, M.; Bock, H.; Urban, N. T.; Lavoie-Cardinal, F.; Willig, K. I.; Eggeling, C.; Jakobs, S.; Hell, S. W. Nature 2011, 478, 204.

(4) Eggeling, C.; Willig, K. I.; Sahl, S. J.; Hell, S. W. Q. Rev. Biophys. 2015, 48, 178.

(5) (a) Butkevich, A. N.; Mitronova, G. Y.; Sidenstein, S. C.; Klocke, J. L.; Kamin, D.; Meineke, D. N. H.; D’Este, E.; Kraemer, P.-T.; Danzl, J. G.; Belov, V. N.; Hell, S. W. Angew. Chem., Int. Ed. 2016, 55, 3290. (b) Donnert, G.; Keller, J.; Medda, R.; Andrei, M. A.; Rizzoli, S. O.; Lührmann, R.; Jahn, R.; Eggeling, C.; Hell, S. W. Proc. Natl. Acad. Sci. U. S. A. 2006, 103, 11440. (c) Staudt, T.; Engler, A.; Rittweger, E.; Harke, B.; Engelhardt, J.; Hell, S. W. Opt. Express 2011, 19, 5644. (d) Schneider,
J.; Zahn, J.; Maglione, M.; Sigrist, S. J.; Marquard, J.; Chojnacki, J.; Kräusslich, H.-G.; Sahl, S. J.; Engelhardt, J.; Hell, S. W. Nat. Methods 2015, 12, 827.

(6) Hell, S. W.; Jakobs, S.; Kastrup, L. Appl. Phys. A: Mater. Sci. Process. 2003, 77, 859.

(7) (a) Nienhaus, K.; Nienhaus, G. U. Chem. Soc. Rev. 2014, 43, 1088. (b) Tiwari, D. K.; Arai, Y.; Yamanaka, M.; Matsuda, T.; Agetsuma, M.; Nakano, M.; Fujita, K.; Nagai, T. Nat. Methods 2015, 12, 515.

(8) Lukinavičius, G.; Umezawa, K.; Olivier, N.; Honigmann, A.; Yang, G.; Plass, T.; Mueller, V.; Reymond, L.; Correa, I. R., Jr.; Luo, Z.-G.; Schultz, C.; Lemke, E. A.; Heppenstall, P.; Eggeling, C.; Manley, S.; Johnsson, K. Nat. Chem. 2013, 5, 132.

(9) Xue, L.; Karpenko, I. A.; Hiblot, J.; Johnsson, K. Nat. Chem. Biol. 2015, 11, 917.

(10) (a) Bossi, M.; Fölling, J.; Dyba, M.; Westphal, V.; Hell, S. W. New J. Phys. 2006, 8, 275. (b) Chen, J.; Cheng, Y. Opt. Commun. 2012, 285, 1404. (c) Deniz, E.; Tomasulo, M.; Cusido, J.; Yildiz, I.; Petriella, M.; Bossi, M. L.; Sortino, S.; Raymo, F. M. J. Phys. Chem. C 2012, 116, 6058.

(11) (a) Bossi, M.; Belov, V.; Polyakova, S.; Hell, S. W. Angew. Chem., Int. Ed. 2006, 45, 7462. (b) Fölling, J.; Polyakova, S.; Belov, V.; van Blaaderen, A.; Bossi, M. L.; Hell, S. W. Small 2008, 4, 134. (c) Polyakova, S. M.; Belov, V. N.; Bossi, M. L.; Hell, S. W. Eur. J. Org. Chem. 2011, 3301. (d) Li, C.; Yan, H.; Zhao, L.-X.; Zhang, G.-F.; Hu, Z.; Huang, Z.L.; Zhu, M.-Q. Nat. Commun. 2014, 5, 5709. (e) Li, C.; Hu, Z.; Aldred, M. P.; Zhao, L.-X.; Yan, H.; Zhang, G.-F.; Huang, Z. L.; Li, A. D. Q.; Zhu, M. Q. Macromolecules 2014, 47, 8594.

(12) (a) Raymo, F. M.; Tomasulo, M. J. Phys. Chem. A 2005, 109, 7343. (b) Yildiz, I.; Deniz, E.; Raymo, F. M. Chem. Soc. Rev. 2009, 38, 1859. (c) Deniz, E.; Tomasulo, M.; DeFazio, R. A.; Watson, B. D.; Raymo, F. M. Phys. Chem. Chem. Phys. 2010, 12, 11630. (d) Bléger, D.; Hecht, S. Angew. Chem., Int. Ed. 2015, 54, 11338.

(13) Bertelson, R. C. Spiropyrans. In Organic Photochromic and Thermochromic Compounds, Volume 1: Main Photochromic Families; Crano, J. C., Guglielmetti, R. J., Eds.; Kluwer Academic Publishers: New York, 2002; pp 11-83.

(14) (a) Szymanski, W.; Beierle, J. M.; Kistemaker, H. A. V.; Velema, W. A.; Feringa, B. L. Chem. Rev. 2013, 113, 6114. (b) Rivera-Fuentes, P.; Wrobel, A. T.; Zastrow, M. L.; Khan, M.; Georgiou, J.; Luyben, T. T.; Roder, J. C.; Okamoto, K.; Lippard, S. J. Chem. Sci. 2015, 6, 1944. (c) Ozcoban, G.; Halbritter, T.; Steinwand, S.; Herzig, L.-M.; KohlLandgraf, J.; Askari, N.; Groher, F.; Fuertig, B.; Richter, C.; Schwalbe, H.; Suess, B.; Wachtveitl, J.; Heckel, A. Org. Lett. 2015, 17, 1517. (d) Li, W.; Chen, Z. W.; Zhou, L.; Li, Z. H.; Ren, J. S.; Qu, X. G. J. Am. Chem. Soc. 2015, 137, 8199.

(15) Marriott, G.; Mao, S.; Sakata, T.; Ran, J.; Jackson, D. K.; Petchprayoon, C.; Gomez, T. J.; Warp, E.; Tulyathan, O.; Aaron, H. L.; Isacoff, E. Y.; Yan, Y. Proc. Natl. Acad. Sci. U. S. A. 2008, 105, 17789.

(16) Koide, Y.; Urano, Y.; Hanaoka, K.; Terai, T.; Nagano, T. ACS Chem. Biol. 2011, 6, 600.

(17) Hammarson, M.; Nilsson, J. R.; Li, S.; Beke-Somfai, T.; Andréasson, J. J. Phys. Chem. B 2013, 117, 13561.

(18) Whelan, J.; Abdallah, D.; Piskorz, K.; Wojtyk, J. T. C.; Dust, J. M.; Nunzi, J.-M.; Hoz, S.; Buncel, E. Phys. Chem. Chem. Phys. 2012, 14, 13684.

(19) It would be interesting to compare the fluorescence quantum yields and lifetimes of the MC and SP forms of $\mathbf{8}$, but this is difficult because thermal recovery of the MC form is fast in polar solvents. The high calculated FRET efficiency in MC-8 (>97\%) is supported by experimental results on related dyads. For example, see: (a) Wu, S.; Luo, Y.; Zeng, F.; Chen, J.; Chen, Y.; Tong, Z. Angew. Chem., Int. Ed. 2007, 46, 7015. (b) May, F.; Peter, M.; Hütten, A.; Prodi, L.; Mattay, J. Chem. Eur. J. 2012, 18, 814

(20) Grotjohann, T.; Testa, I.; Reuss, M.; Brakemann, T.; Eggeling, C.; Hell, S. W.; Jakobs, S. eLife 2012, 1, e00248. 